\title{
TECNOLOGIA DO APOIO E DEMOCRATIZAÇÃO NA GESTÃO DO SISTEMA ÚNICO DE SAÚDE: REVERBERAÇ̃̃ES DA ANÁLISE INSTITUCIONAL NO CAMPO DA SAÚDE COLETIVA
}

SUPPORT TECHNOLOGY AND DEMOCRATIZATION IN THE MANAGEMENT OF THE BRAZILIAN NATIONAL HEALTH SYSTEM: REVERBERATIONS OF INSTITUTIONAL ANALYSIS IN THE COLLECTIVE HEALTH SCOPE

TECNOLOGÍA DE APOYO Y DEMOCRATIZACIÓN EN LA GESTIÓN DEL SISTEMA ÚNICO DE SALUD BRASILEÑO: REVERBERACIONES DE LA INSTITUCIONAL ANÁLISIS EN EL ÁMBITO DE LA SALUD COLECTIVA

Carolina Eidelwein ${ }^{*}$

Simone Mainieri Paulon ${ }^{* *}$

\begin{abstract}
RESUMO
O presente trabalho apresenta uma investigação acerca dos processos, em curso no país, de institucionalização da metodologia do apoio no Sistema Único de Saúde - SUS. Na composição de diferentes arranjos constitutivos de práticas de apoio no campo da Saúde Coletiva, despontam diversos pontos de aproximação e rupturas com o referencial da Análise Institucional Socioanalítica. O modo como essa abordagem institucionalista tem subsidiado teórica e metodologicamente as práticas de apoio no SUS, com ênfase nas contribuições trazidas ao debate da democratização dos processos de trabalho nesse campo, são o mote deste artigo. Ao final, aponta-se o caráter de inacabamento do apoio como potência constitutiva dessa tecnologia relacional no âmbito da Saúde Coletiva.
\end{abstract}

Palavras-chave: Apoio Institucional. Políticas Públicas de Saúde. Análise Institucional. Democracia.

\begin{abstract}
The present paper presents a research which proposed to investigate the processes of the institutionalization of the supporting methodology of the Brazilian National Health System (SUS), currently in progress in the country. In the composition of various arrangements to support practices in the collective health scope emerge various points of approach and breaks with the reference of Socio- analytical Institutional Analysis. How this institutional approach has subsidized theoretically and methodologically
\end{abstract}

\footnotetext{
* Mestre em Psicologia Social e Institucional (UFRGS) - Universidade Federal do Rio Grande do Sul/Escola de Saúde Pública SES-RS. Av. Ipiranga, 6311, CEP 90610-001, Porto Alegre-RS. E-mail: caroleidelwein@gmail.com

** Doutora em Psicologia Clínica (PUC SP), Universidade Federal do Rio Grande do Sul. E-mail: simone.paulon@ufrgs.br
} 
practical support in SUS, with emphasis on the contributions made to the discussion of democratization of work processes in this field, are the theme of this article. Finally, it points out the supporting character of incompleteness as a constitutive power of this relational technology in the context of public health.

Keywords: Institutional Support. Public Health Policies. Institutional Analysis. Democracy.

\section{RESUMEN}

El presente documento presenta una investigación de los procesos de institucionalización de la metodología de apoyo en el Sistema Único de Salud (SUS), actualmente en curso en el país. En la composición de diferentes arreglos que constituyen las prácticas de apoyo en el campo de la salud pública surgen diferentes puntos de aproximación y rotura con la referencia de Análisis Institucional Socioanalítica. Cómo este enfoque institucionalista ha subvencionado teóricamente y metodológicamente las prácticas de apoyo en el SUS, con énfasis en las contribuciones hechas a la discusión de la democratización de los procesos de trabajo en este campo, son el tema de este artículo. Por último, se señala el carácter de incompletitud del mecanismo de apoyo como el potencial constituyente de esta tecnología relacional en el contexto de la salud pública.

Palabras claves: Apoyo Institucional. Políticas de Salud Pública. Análisis Institucional. Democracia.

\section{INTRODUÇÃO}

ste trabalho apresenta uma investigação acerca dos modos como a tecnologia do apoio vem sendo utilizada, e recentemente institucionalizada, no contexto da saúde coletiva brasileira. Trata-se de uma cartografia realizada num campo em que se entre-tecem linhas de formação, pesquisa, atenção e gestão, na política pública de saúde, como um mergulho intensivo na experiência de trabalho-pesquisa no Sistema Único de Saúde - SUS ${ }^{1}$.

Nesse trajeto investigativo, deparamo-nos com reverberações da Análise Institucional Socioanalítica na composição de diferentes arranjos constitutivos de práticas de apoio no campo da Saúde Coletiva. É dessas reverberaçõos que trataremos a seguir. A fim de perscrutá-las, o texto situa brevemente algumas condições de emergência das práticas de apoio no SUS, bem como apresenta

\footnotetext{
1 Experiência ligada ao curso de Mestrado em Psicologia Social e Institucional - UFRGS, em articulação com a pesquisa multicêntrica "Formação em Humanização do SUS: avaliação dos efeitos dos processos de formação de apoiadores institucionais na produção de saúde nos territórios do Rio Grande do Sul, Santa Catarina e São Paulo" (UFRGS/UFSC/UNESP-Assis), entre 2012 e 2014.
} 
os principais arranjos de apoio encontrados no campo pesquisado, discutindo pontos de aproximação e rupturas com o referencial institucionalista. Ao final, busca precisar quais arranjos compóem essa tecnologia relacional, indicar seu recente processo de institucionalização, para afirmà-la, fundamentalmente, em seu inacabamento, constitutivo de sua potência de intervenção.

O Movimento da Reforma Sanitária Brasileira e a consequente consolidação do SUS são resultantes da conquista, pela população brasileira, de espaços políticos para a manifestação, articulação, reivindicação e exigências de direitos frente ao Estado, solidificando a noção de participação e ação coletivas na sociedade civil (Yasui, 2010). São experiências de conexão entre diferentes movimentos sociais e entre forças que estão para além e aquém do Estado, indicativas de que Estado e governo não podem ser as únicas expressões do coletivo em nosso contexto social - se assim fosse, estaríamos em uma via de privatização das políticas públicas. A política, para ser política pública, necessariamente inclui a sociedade civil ou, dito de outra forma, inclui forças em posição de exterioridade em relação ao Estado. À medida que temos no Brasil o funcionamento de uma máquina estatal em que a res publica está nela e contra ela, faz-se necessário constante investimento desejante para que a política pública seja de fato pública (Benevides \& Passos, 2005).

Nessa direção, como obra aberta, sempre inacabada, o SUS vem produzindo avanços e tensões. Em um ensaio denominado SUS depois de vinte anos: reflexões sobre o direito à atenção à saúde, Campos observa que, apesar da expansão da rede de serviços de saúde, o "movimento de estatização do setor vem ocorrendo de modo concomitante com a predominância, na sociedade brasileira e no mundo, de um discurso a favor do mercado e pelo afastamento do Estado da economia e das questôes sociais" (Campos, 2008, p. 1).

Para Fleury (2009), o maior desafio da fase atual da reforma sanitária envolve a garantia do acesso dos usuários, com reorientação das lógicas burocrática e profissional que organizam o sistema, em direção a outra lógica que, por ter o usuário como central ao sistema de saúde, garanta a humanização, a eficácia e a resolutibilidade do cuidado. $\mathrm{Na}$ mesma direção, Bertussi (2010) destaca como problemático no SUS o predomínio da centralização das decisões tomadas no topo da pirâmide, da hierarquia baseada no princípio da unidade de comando, a adoção majoritária de estruturas piramidais de poder e a rigidez e impessoalidade no trabalho em saúde. Segundo essa autora, são práticas que acarretam falta de flexibilidade na gestão do sistema e afastamento das necessidades de saúde da população. 
Diante de tais desafios enfrentados na implementação do SUS, diversos arranjos organizacionais e referenciais teórico-metodológicos têm sido propostos como modos de reformulação do processo de trabalho nos serviços e nas redes de atenção, gestão e educação em saúde. Pasche e Passos (2010a) destacam que as experiências acumuladas nesse campo indicam a importância da inovação trazida pelas tecnologias relacionais ou tecnologias leves (Merhy, 2002). Essas tecnologias pressupõem a capacidade de sujeitos e organizações colocarem em questão as formas instituídas do trabalho em saúde, identificando essa face que pode se apresentar enrijecida e apostando em suas forças instituintes, forças capazes de mobilizar ações de mudança nos processos de trabalho (Santos-Filho \& Barros, 2007).

Assim, inspirados nos movimentos sociais que emergiram no país na segunda metade da década de 1970 e, mais recentemente, em junho de 2013, entendemos que, ao invés de incidir sobre as formas - o SUS, a política X, Y, Z ou mesmo o Estado -, intensificar a conexão com as forças do Fora do Estado com o que é público, de todos e de qualquer um - interferir no comum - pode ser um caminho profícuo para a consolidação do SUS.

Nesse sentido, abordaremos algumas propostas de reformulação dos processos de trabalho no SUS, no âmbito das práticas hoje denominadas como "apoio", as quais têm sido uma das principais novidades no trabalho em saúde e que parecem caminhar na direção da conexão e coletivização dos processos de democratização da saúde no Brasil (Barros, Guedes \& Roza, 2011; Bertussi, 2010; Campos, 2000, 2003, 2007a; Oliveira, 2011; Pasche \& Passos, 2010a, 2010b; Penido, 2013; Vasconcelos \& Morschel, 2009).

Dessa forma, as propostas de Apoio Paideia, de Apoio Institucional na Política Nacional de Humanização e de Apoio Rizomático, serão apresentadas a seguir como arranjos distintos. Circunscrevemos algumas proposiçóes, entre tantas outras, à medida que são precursoras na sistematização de experimentações desse modo de fazer o trabalho em saúde que se incluem no campo das práticas hoje denominadas como "apoio". Salientamos, porém, que no cotidiano essas práticas não apresentam tal nitidez em suas fronteiras, compondo bricolagens entre si e com outras ferramentas inventadas para potencializar encontros e produzir saúde coletiva - passando a estabelecer múltiplas conexóes, desdobramentos e atravessamentos. Oliveira (2011) alerta que esses arranjos

Não devem ser tomados como fins em si mesmos, modelos a serem implantados para fazer 'dar certo' o SUS, mas sim como elementos agenciadores de sujeitos e processos em torno do projeto ético-estético-político do SUS. E, mais amplo ainda, de processos de democratização institucional. (Oliveira, 2011, p. 28). 
Destacamos que o Apoio Paideia consiste em uma proposta teóricometodológica que inspira o Apoio Institucional, tal como proposto pela Política Nacional de Humanização, assim como deu origem, também, ao Apoio Rizomático. Vários conceitos oriundos do Método Paideia estão presentes nessas duas proposiçóes, ainda que cada uma delas se fundamente também em outros referenciais.

O termo "Apoio Institucional” surge no interior do Método de Apoio Paideia. Esse termo foi concebido como sendo uma forma de aplicação do referencial Paideia nas relações entre profissionais e gestores. Mesmo no âmbito da Política de Humanização, o uso do termo Apoio Institucional não aparece desvinculado da rede conceitual Paideia. Quando incorporado pelo Ministério da Saúde em diversos outros âmbitos, como por exemplo no Apoio Integrado ${ }^{2}$, o termo Apoio Institucional ganha maior destaque, sendo agregado a outros referenciais.

\section{DO APOIO PAIDEIA}

A teoria e o método Paidéia, ou método da roda, como também é chamado, propostos por Campos (2003) no âmbito da Saúde Coletiva, fundamentamse em teorias e práticas que procuram articular o campo da política e da gestão com saberes e experiências originários da Psicanálise, da Pedagogia e da Análise Institucional. Consistem, basicamente, em uma metodologia de trabalho sistemático para aumentar a capacidade das pessoas de agirem sobre o mundo, favorecendo, por meio da política, a constituição de sujeitos reflexivos e operativos. O autor observa que ao trabalhar em equipe, ao conviver em movimentos sociais, ao integrar organizações como trabalhador, usuário ou aluno, se estará necessariamente diante da tarefa de fazer política.

Em suas produções, Campos (2003,2007a) denomina esse trabalho sistemático com coletivos, no sentido de ampliar a capacidade de análise e intervenção dos sujeitos no campo do trabalho em saúde, de Apoio Paidéia. Destaca que o conceito de Paidéia, desde sua origem na Grécia Clássica, enfatiza a capacidade de compreender e de intervir sobre o mundo como um aprendizado social que depende de esforço sistemático e planejado. Trata-se de uma formação para a vida como cidadão, formação de sujeitos capazes de exercer a democracia. No Método Paidéia, esse sanitarista define a função de apoiador da seguinte forma:

a) um modo complementar para realizar coordenação, planejamento, supervisão e avaliação do trabalho em equipe;

\footnotetext{
2 Estratégia desenvolvida pelo Ministério da Saúde que tem como objetivo potencializar a ação federal no processo de cooperação interfederativa, buscando fortalecer, consequentemente, a gestão do Sistema Único de Saúde na ampliação do acesso e melhoria da qualidade das açōes e serviços de saúde.
} 
b) um recurso que procura intervir com os trabalhadores de forma interativa;

c) uma função que considera que a gestão se exerce entre sujeitos, ainda que com distintos graus de saber e de poder, e que produz efeitos sobre os modos de ser e de proceder desses sujeitos e das organizações;

d) depender da instalação de alguma forma de cogestão (Campos, 2000; Oliveira, 2011).

No mesmo trabalho, Campos (2000) apresenta os eixos de conformação do método, uma estruturação em quatro eixos a partir de um campo teórico referenciado em estudos, reflexóes e experiências do sanitarista em diferentes contextos institucionais. No primeiro eixo, discute o caráter Anti-Taylor do método, tecendo uma análise sobre os meios de intervenção da racionalidade gerencial taylorista e propondo, em contrapartida, unidades de produção/ coletivos organizados para a produção. No segundo eixo, inscreve o método no paradigma da democratização institucional, da cogestão e da constituição de sujeitos com capacidade de análise e de intervenção. Oliveira (2011) comenta que esse eixo demarcaria uma espécie de "autenticação" de uma experiência de Apoio Paidéia: "se não há arranjos de participação efetiva e de deliberação conjunta entre os sujeitos, processos de democratização institucional, não há método da roda”. No terceiro eixo, denominado Por uma reconstrução conceitual e prática do trabalho, propóe uma tentativa de reconstrução do sentido do trabalho e de suas finalidades. Finalmente, no quarto eixo, coloca o método da roda como modo de possibilitar a análise e o desvio das práticas sociais para produção de mais autonomia e liberdade, em vez de controle e dominação, em uma organização. Segundo Oliveira, o conceito de produção é "designado sempre como uma coprodução dialética entre desejos e interesses disputados por atores institucionais", inscrevendo uma visão dialética de mundo (Oliveira, 2011, p. 32).

Nessa direção, Campos (2000) postula também um arranjo organizacional para o trabalho em saúde denominado equipes de referência e apoio especializado matricial, o qual se sustenta nas diretrizes de vínculo terapêutico, transdisciplinaridade do saber e das práticas e gestão das organizaçôes como dispositivo para produção de grupos de sujeitos. Penido (2013) esclarece que a aposta de Campos é de que o arranjo pode ser capaz de produzir alteraçôes na subjetividade e na cultura dominante entre os profissionais de saúde. Ressalta que "o apoio matricial se incumbe de oferecer retaguarda assistencial e suporte técnico-pedagógico às equipes de referência, fundado no pressuposto de que 
nenhum especialista, isoladamente, pode assegurar uma abordagem integral" (Penido, 2013, p. 22).

Importa destacar a partir daí que o método Paidéia opera com a ideia de "ofertas", buscando produzir uma tensão dialética entre diretividade e não-diretividade da política, da gestão, da clínica e da saúde coletiva. Nesse sentido, de algum modo, o método estará imbuído em produzir um "trabalhador funcional". Conforme Campos (2007b) explica a seguir, vemos que existe, desde essa perspectiva, um objetivo previamente traçado a ser buscado pela organização:

\begin{abstract}
Gramsci falava na importância da reforma intelectual e moral; cognitiva e afetiva, política e ética diríamos hoje. O velho Aristóteles (384-322 a.C., 1987) escreveu: "Se não foste educado para seres bom, será obrigado pelo Estado a te tornares". Esta formação para a cidadania, para viver na Polis dependeria da educação das pessoas (Paidéia), da ética e da política. E ele continua: "Não é irrelevante, portanto, se formamos hábitos de um ou outro tipo..., faz uma grande diferença, na verdade toda a diferença". Cabe, portanto, aos legisladores, governantes (gestores da coisa pública) «... tornar bons os cidadãos incutindo-lhes bons hábitos”. A gestão é uma continuação da política com os mesmo e outros recursos, a reforma moral e intelectual continua nas organizaçôes e durante o trabalho e o governante, o método de gestão, tudo isto participa das sínteses singulares realmente existentes. (Campos, 2007b, p. 353-354).
\end{abstract}

\title{
3. O APOIO INSTITUCIONAL NA POLÍTICA NACIONAL DE HUMANIZAÇÃO
}

Outra proposta elaborada com objetivo de interferir nos modos de gerir, cuidar e formar no âmbito do SUS é a Política Nacional de Humanização da Atenção e Gestão do SUS (PNH). Com um arcabouço teórico-metodológico constituído pela composição de múltiplos referenciais, tem na função apoio sua estratégia de intervenção por excelência. Abrange as concepções advindas do Método Paidéia e lança mão de trabalhos de sanitaristas brasileiros no campo da Saúde Coletiva, de referenciais oriundos do Institucionalismo Francês, com contribuições de Lourau e Lapassade e, ainda, da Esquizoanálise de Deleuze e Guattari (2002). Tal política do Ministério da Saúde foi formulada em 2003 como política transversal, de forma que

\footnotetext{
A PNH apresenta-se não mais como um programa, mas como uma política para se reinventar modos de gerir e modos de cuidar, tomando por diretrizes o acolhimento, a ampliação da clínica, a gestão democrática, a valorização do trabalhador e a garantia dos direitos dos usuários. Estas diretrizes se apoiam em três princípios: a ampliação da transversalidade ou aumento do grau de abertura comunicacional intra e intergrupos, favorecendo a capacidade de interferência mútua entre sujeitos e a sua capacidade de deslocamento subjetivo; a inseparabilidade entre gestão e atenção; e, finalmente, a aposta no protagonismo dos sujeitos em coletivos (Pasche, Passos \& Hennington, 2011, p. 4544).
} 
O apoio institucional, nesse contexto, é proposto como uma função gerencial que busca a reformulação do modo tradicional de se fazer coordenação, planejamento, supervisão e avaliação em saúde. Opera em "uma região limítrofe entre a clínica e a política, entre o cuidado e a gestão - lá onde estes domínios se interferem mutuamente" (BRASIL, 2008), trabalhando no sentido da transversalidade das práticas e dos saberes no interior das organizaçôes.

Barros et al. (2011) apresentam o apoio institucional como estratégia de fomento à gestão compartilhada dos processos de trabalho exercida nas práticas cotidianas concretas, nas quais todo trabalhador é gestor de seu trabalho. Afirmam que o sentido da prática do apoio institucional está no acompanhamento e na construção dos processos/percursos de transformação das práticas, colocando-se o apoiador ao lado dos sujeitos que vão experimentar/produzir as mudanças não é o apoiador quem produz a mudança ou é a causa da transformação.

Para as autoras, que partem da compreensão de que toda mudança nas práticas de saúde envolve análise dos processos de trabalho, o método do apoio propõe colocar em análise as formas como o trabalho vem sendo organizado. A partir das análises sobre seus processos de trabalho, o coletivo dispõe da matéria para a construção dos planos de ação que se orientam pela transformação do trabalho em saúde, como forma de, em seu papel de cuidadores, seus membros redirecionarem o cuidado a si e se engajarem na construção de novas práticas de cuidado. Cuidar-se - colocar coletivamente em análise os processos vividos cotidianamente - é condição para o cuidado coletivo, nessa perspectiva em que gestão e atenção não se separam (Barros et al., 2011).

O apoio, portanto, na perspectiva trabalhada por essas autoras, pressupõe que, para mudar as práticas e perenizar as mudanças, é preciso incluir as pessoas nos processos decisórios e ampliar a democracia institucional. Como sintetizam alguns sanitaristas que têm se ocupado desse tema:

Uma das formas de ampliar o sentido do trabalho e a vontade de fazer a implicação e a responsabilização dos sujeitos é através da efetiva participação na gestão dos processos de trabalho, portanto a inclusão das pessoas, de fato, nos processos de tomada de decisão nas organizaçóes. De modo geral, os trabalhadores se sujeitam e sofrem a gestão e pouco participam dela. A PNH toma a cogestão e a gestão compartilhada como uma diretriz, apostando na democratização das relações de poder como um valor e como um requisito para a ampliação da corresponsabilização dos trabalhadores (Pasche et al., 2011, p. 4546).

Ressalte-se, a partir do debate acerca do método do apoio, que ele diz respeito à aposta em "um" modo de fazer, que não está identificado como "o", mas como "um" modo possível de realização de mudanças no campo da saúde. 
Em sua formulação geral, esse método "deve sempre guardar uma franja de indeterminação, uma dose de inespecificidade, a fim de que sejamos forçados a precisá-lo a cada encontro". Se entendermos a prática do apoio como dispositivo, necessariamente trabalharemos com a noção de que um dispositivo é sempre transitório (que faz transitar), pois sua função é de disparo, por isso não pode ficar preso em si mesmo. Um dispositivo aponta sua própria dissolução como recurso de método trabalhado com aquele coletivo singular. "Aferrar-se no dispositivo é propor a morte da continuidade dos movimentos instituintes que criaram as condições político-institucionais para a experimentação do apoio" (Passos \& Pasche, 2010b, p. 442-443).

Se o dispositivo é sempre transitório, em vez de modos pré-formatados, o apoiador preferencialmente trabalha com dispositivos que se constituem em acontecimentos do cotidiano para provocar a análise dos processos de trabalho, sejam eles pesquisas, oficinas, atividades de matriciamento, visitas institucionais, atividades de formação etc., praticados em rodas que favoreçam a circulação da palavra. Nesses espaços, o apoiador faz aparecer esse emaranhado de forças que sustentam os conflitos, com a tarefa de dar emergência a eles. $\mathrm{O}$ apoiador fica atento para os sentidos que expressam assujeitamento do grupo e para outros que fornecem caminhos de desvio, possibilidades de autonomia e protagonismo e de criação de novos modos de cuidar e de gerir o trabalho, lembrando que as condiçôes para a mudança nem sempre são imediatamente possíveis (Barros et al., 2011).

\section{DE UM APOIO RIZOMÁTICO}

Bertussi (2010), em sua tese de doutoramento, afirma que os problemas enfrentados no SUS não se resolvem só pelo acesso e tampouco estão relacionados apenas às questôes de mudanças e de reformas macroestruturais, mas se referem à micropolítica do processo de trabalho. A autora parte da ideia de que, "apesar de haver governo, a gestão não é única, nem exercida somente a partir do núcleo central, já que há vários coletivos operando, alguns institucionalmente na gestão, outros operando em outros âmbitos, mas atravessando-se mutuamente" (Bertussi, 2010, p. 22).

Sua investigação cartográfica persegue a manifestação e busca captar a expressão dos diferentes "coletivos desejantes" que operaram na Secretaria Municipal de Saúde de João Pessoa, no Estado da Paraíba, para analisar como atuaram na constituição de uma gestão municipal em saúde. Com base nessa experiência e em seus desdobramentos, o trabalho em foco faz uma proposição a qual denomina "apoio rizomático", que não se configura como arranjo 
organizacional propriamente dito, mas apresenta pistas conceituais que situam o plano constitutivo dessa concepção de apoio.

Em tal proposta, que também advém das proposições inicialmente colocadas pelo Método Paideia e, portanto, dialoga com os referenciais institucionalistas que o sustentam, "não há separação entre clínica e gestão e o apoio se constitui na micropolítica do encontro entre apoiador e as equipes de saúde, mobilizando distintas ofertas, relacionadas à organização do processo de trabalho e à produção do cuidado, de acordo com as necessidades das equipes" (Bertussi, 2010, p. 112113). A autora explicita que "não se faz a separação entre apoio institucional e apoio matricial. Até porque o encontro de saberes entre diferentes profissionais é só um dos elementos necessários para a qualificação e para a continuidade do cuidado" (Bertussi, 2010, p. 170-171).

A referida tese apresenta quatro principais planos constitutivos do apoio, que são compostos pelo conceito de devir, pelo conceito de espaço intercessor, por um modo rizomático e por uma caixa de ferramentas. No primeiro plano, Bertussi explica que, ao referirem devir, Deleuze e Guattari não pretendem estabelecer um curso em uma evolução, em um progresso ou em um desenvolvimento, mas, em outro sentido, os signos de uma involução. Então, o devir-apoiador se produziria na tentativa de aprender a ultrapassar uma subjetividade fundamentada no eu, a deslocar do ser do eu e da consciência para os devires. Indica que "é necessário reconhecer que não se pode aprender sem começar a se desprender. A se desprender, antes de tudo e sempre, de si” (Bertussi, 2010, p. 123).

No segundo plano, o espaço intercessor designa, conforme a autora, o que se produz nas relações entre sujeitos e não tem existência fora do momento do encontro em ato, no qual são os "entres" que se colocam como instituintes na busca de novos processos. O "entre" configura um espaço/produção dependente do encontro, transitório e que não pode ser reproduzido por nenhuma parte isoladamente, pois a potência do "entre" é distinta da potência de cada um. Assim, a intercessão é um produto que existe para os "dois" em ato, não tendo existência sem esse momento, em processo, e no qual os "inter" se colocam como instituintes em um processo muito próprio desse sujeito coletivo novo que se formou.

A autora considera que esse espaço que se configura no momento dos encontros define um espaço de autogoverno, em que se expressam desejos, projetos, tecnologias disponíveis por parte de cada trabalhador, num exercício permanente de "negociação" com os projetos políticos da gestão. Então, em função do trabalho vivo em ato e dos espaços intercessores, todos os trabalhadores de saúde são gestores, pois fabricam cotidianamente o modelo de atenção, em disputa ou consonância com as propostas da gestão e com as propostas dos demais trabalhadores. 
Quanto ao modo rizomático, que seria o terceiro plano constitutivo do apoio, a autora recorre novamente a Deleuze e Guattari (2002), que utilizam o conceito de rizoma para explicar a noção de complexidade que envolve os fenômenos contemporâneos. "Para eles existem diferenças profundas entre rizoma e árvore. A árvore está ligada à ideia de fixação a um ponto, uma ordem, enquanto em rizoma existem princípios de conexão e de heterogeneidade: qualquer ponto de um rizoma pode ser conectado a qualquer outro" (Bertussi, 2010, p. 126). Assim, aponta que um terceiro plano de constituição/análise diz respeito a como se produzem as relações no organograma de uma secretaria de saúde de modo arborescente ou rizomático -, pois as mesmas se dão em disputa, e a produção de coletivos, ou melhor, os coletivos em ação configuram-se com maior potência quando há brechas para o debate intenso e cotidiano do que fazer, como fazer e por que fazer a gestão. Nesse sentido, explica que o arranjo matricial/matriciamento pode ser a expressão do organograma rizomático, uma forma de organização das relações por meio da necessidade de conexão, e não porque a priori se tem o comando.

Finalmente, o quarto e último plano que atravessa essa construção é a caixa de ferramentas do apoiador para operar o apoio às equipes de saúde. $\mathrm{Na}$ experiência analisada, concebia-se uma

caixa de ferramentas que possibilitassem aos apoiadores lidar com os contextos que surgissem em ato. Não uma chave que finalmente pudesse permitir abrir o cofre, revelando soluções mágicas para que tudo passasse a ser perfeito na produção das relações entre apoiadores e trabalhadores das ESF (Bertussi, 2010, p. 87).

Refere-se à produção de ferramentas que permitissem percorrer e lidar com as relaçóes, apreender seu relevo, construir vínculo, misturar-se às equipes, ampliando as possibilidades de invenção e encontro com os trabalhadores.

A autora propóe pensarmos o matriciamento como alternativa ao vertical, a fim de produzir relações horizontais entre profissionais de distintas áreas/projetos e campos de conhecimento. Adverte, porém, que tais "arranjos são mutáveis e estão sempre em transformação - por isso pensar coletivamente sobre o trabalho é um movimento sem fim" (Bertussi, 2010, p. 166).

\section{APOIO E ANÁLISE INSTITUCIONAL: CONVERSAÇÕES}

Destacamos que, neste percorrido por algumas proposições metodológicas de apoio - cada uma contendo traços singulares, que ora as aproximam e ora as distanciam entre si -, um elemento aparece invariavelmente: a inspiração nos referenciais socioanalíticos. 
Inspiração que vem à cena quer se trabalhe em uma perspectiva dialética, quer se tome o apoio como uma "função institucional", ou, ainda, quando se compreende na perspectiva de uma filosofia da diferença como a tese acima referida de Bertussi o faz. No primeiro caso, a leitura marxista de um mundo sobredeterminado poderia implicar que o apoio seja considerado um subterfúgio capaz de "aumentar a capacidade das pessoas de agir sobre" ele, vislumbrado como recurso para "formação de sujeitos capazes de exercer a democracia", como método portador de "eixos de conformação" ou como "arranjo capaz de produzir alterações na subjetividade e na cultura". Quando se entende essa tecnologia como uma "função" que busca a "ampliação da transversalidade", "favorecer a capacidade de interferência mútua entre sujeitos e sua capacidade de deslocamento subjetivo", operando como "dispositivo transitório", o apoio ganha mais um "sentido de acompanhamento" e "construção de processos/percursos de transformação das práticas". Nessa segunda proposição, tal como bem explorada pela $\mathrm{PNH}$, o apoiador coloca-se "ao lado dos sujeitos que vão experimentar/ produzir mudanças", guardando uma dimensão de "indeterminação", atento ao que se apresenta nos coletivos como "desvio", como possibilidade de autonomia e protagonismo, considerando a "dissolução como recurso do método". Tem-se, ainda, na perspectiva do apoio como trabalho que opera de modo "rizomático", um terceiro enfoque na "micropolítica do processo de trabalho", com uma concepção de que "a gestão não é única", que segue "pistas conceituais" apresentadas em "planos constitutivos", interessado em "encontro de saberes", buscando "desprender-se de si" e a instalação de "espaços de autogoverno". A ênfase aqui é no entendimento de que o "agir em saúde" comporta "tensões autonomia versus controle", e o apoio apostaria em "desproduzir lugares de comando" e "desmanchar hierarquias"...

Ainda que a formulação do método Paidéia tenha originado a concepção de apoio institucional da qual derivam as demais produções teórico-metodológicas nesse âmbito e que todas as três manifestem sua fundamentação em contribuições institucionalistas, sublinhamos acima as escolhas conceituais que sustentam as perspectivas apresentadas no intuito de dar a ver as múltiplas nuances que compõem esse intrincado plano do apoio.

É com esse objetivo que propusemos colocar em análise alguns aspectos $\mathrm{da}(\mathrm{s})$ metodologia(s) de apoio, entendendo que o trabalho de análise busca incidir na abertura dos graus de transversalidade apresentados pelas organizações, abertura às vozes minoritárias, aos movimentos desejantes que pedem passagem. Coimbra adverte que os sistemas teóricos, de um modo geral, são extremamente fechados, com suas "verdades" que se situam à margem do que a realidade social lhes está dizendo. E "ao ignorar a transversalidade, estão decididamente mortos, institucionalizados" (Coimbra, 1995, p. 73). 
Vai nessa direção a articulação que os analistas institucionais - e quiçá os apoiadores - têm buscado fazer entre movimentos sociais, teoria, prática e intervenções concretas - ela advém da necessidade de se criar incessantemente novas estratégias, de não se deixar cair nas malhas do instituído, nas tentações do poder. Para Coimbra, esse tem sido o grande desafio enfrentado pela Análise Institucional ao acompanhar os movimentos da realidade social, ao aprender com eles, ao tentar negar os modelos de atuação definidos e, por isso mesmo, estáticos (Coimbra, 1995).

Interessa-nos aqui, especificamente, mapear pontos de aproximação e de ruptura entre o que tem sido formulado no âmbito do apoio e as proposições da Análise Institucional. Vasconcelos e Morschel (2009) articulam o objetivo central do apoio ao do analista institucional. Para as autoras, é função que compete ao apoiador fomentar análises sobre a dinâmica de relaçôes, de poderes, de práticas, de significações, de afetos que permeiam o estabelecimento de saúde, colocandoas a serviço de todas as pessoas aí situadas, conferindo-lhes, assim, meios para pensarem sobre sua função e funcionamento, aliando-se a eles na análise dos ranços institucionais e problemas organizacionais e na subsequente abertura de sentidos, construção de redes e de práticas inéditas, discursivas e não discursivas.

Segundo Ceccim (2005), intelectuais especialistas e consultores usualmente trabalham com dados gerais que possibilitam identificar a existência dos problemas e sugerir sua explicação, porém não permitem compreender sua singularidade, sua vigência subjetiva, suas conexões de sentido local. Para o autor, no entanto, os desconfortos e as incertezas experimentados no cotidiano do trabalho têm de ser intensamente admitidos, vividos, percebidos: "não se contata o desconforto mediante aproximações discursivas externas". (Ceccim, 2005, p. 165). Ressalta que a vivência e/ou a reflexão sobre as práticas vividas é que podem produzir o contato com o desconforto e, consequentemente, a disposição para produzir alternativas de práticas e de conceitos, para enfrentar o desafio de produzir transformações.

Assim, o papel das práticas educativas deve ser crítica e incisivamente revisto para que almeje a possibilidade de pertencer aos serviços/profissionais/estudantes a que se dirigem, de forma que os conhecimentos que veiculam alcancem significativo cruzamento entre os saberes formais previstos pelos estudiosos ou especialistas e os saberes operadores das realidades detidos pelos profissionais em atuação -, para que viabilizem autoanálise e principalmente autogestão (Ceccim, 2005, p. 166).

Caminha nesse sentido a problematização proposta pelos institucionalistas que consiste na politização dos especialismos. Lourau afirma que "a sociologia 
deve ser feita por todos, não apenas por um”, já que a política não apenas está na vida cotidiana, mas ela é a vida cotidiana. A análise, para ele, não é o oposto da ação: a ação é a análise. Ele introduz a ideia de que a ação é um analisador, inclusive da análise instituída como atividade de especialista, para evitar confundir sob um mesmo nome coisas tão diferentes como a análise feita por um especialista dotado de jargóes e a análise no sentido que ele propõe: uma análise social coletiva (Lourau, 2004a, p. 124).

Vasconcelos e Morschel (2009) vão ao encontro dessas proposições quando aproximam o apoio a uma lógica, a uma metodologia por meio da qual se pretende desconstruir a ideia de que uma supervisão, um "superolhar", uma "cabeça pensante" vinda do "exterior", sem envolvimento com o espaço-tempo institucional, com o cotidiano dos serviços, possa prover os corpos executantes de respostas apuradas. Para as autoras, ao contrário, o apoio institucional tem como objetivo-chave justamente o de construir espaços de análise e interferência no cotidiano, potencializando análises coletivas de valores, saberes e fazeres e, desse modo, implementar e mudar práticas.

Paulon, Pasche e Righi (2014, p. 810) lembram que "o apoiador institucional surge em diferenciação à figura clássica de um supervisor do trabalho (de inspiração da gestão do trabalho na área industrial) e, também, ao analista institucional". Ao enunciarem essa diferenciação no texto ora citado, os autores apontam uma diferença fundamental que está colocada entre o que usualmente se tem proposto como apoio institucional e o que propõe a Análise Institucional em relação à concepção de gestão. $\mathrm{O}$ apoio tem como marcador a ideia de cogestão, já a Análise Institucional tem como conceito motriz de sua política o conceito de autogestão.

Lourau (1993) destaca que vivemos sempre, em todos os lugares, sob a heterogestão. E que a vivemos, geralmente, como coisa natural. "A autogestão que existe, a que tem podido existir, acontece dentro de uma contradição total, já que a vida cotidiana [...] se passa no terreno da heterogestão". Segundo ele, preferimos, cotidianamente, não nos colocar muitos problemas e assim, "permitindo" que se dê a heterogestão, "confiamos" a "autogestão" a outras pessoas. A isso alguns, Marx, por exemplo, chamam "alienação". "Amamos nossa 'alienação'. Sentimos que é muito dolorosa a análise de nossas implicações; ou melhor, a análise dos 'lugares' que ocupamos, ativamente, neste mundo" (Lourau, 1993, p. 14).

A autogestão não é estudável em manuais; é uma construção política permanente que se apoia, principalmente, sobre a restituição. A restituição consiste na tarefa de analisar coletivamente a situação presente, no presente, em função das diversas implicações de cada um com e na situação (Lourau, 1993). 
Nesse sentido, em lugar de utopia, as experimentações de autogestão podem ter lugar como exercício heterotópico, de expansão da vida. É invenção de lugares, de existências, de espaços de contraposicionamentos, demandando crítica à sociedade e gestação de nova sociedade (Passetti, 2002).

Aguiar e Rocha (2007) destacam que a proposta institucionalista de produção cooperativa e autogestionária opera na perspectiva de fragilização das hierarquias burocráticas e das divisões em especialidades que fragmentam o cotidiano e isolam os profissionais. Para elas, as estratégias de intervenção têm como alvo a rede de poder e o jogo de interesses que se fazem presentes no campo da investigação, colocando em análise os efeitos das práticas no cotidiano institucional, desconstruindo territórios e facultando a criação de outros modos de existência.

Todavia, embora incorpore o referencial institucionalista em alguns aspectos, o apoio institucional tem sua origem em um campo de coerência no qual a autogestão não seria possível e inclusive seria indesejável em nossa organização social, pois resultaria em uma espécie de "autogoverno, com características exclusivistas e excludentes", em que caberia a existência de poder e dominação absolutos. Em substituição a essa ideia, utiliza-se o conceito de cogestão para fixar a proposta de governo em que todos teriam graus de autonomia, sem haver decisões isoladas ou não compartilhadas, como suspostamente haveria em experimentações autogestionárias de organização coletiva (Campos, 1998, p. 867).

A concepção do conceito de cogestão, bem como as tentativas de sua operacionalização no SUS, parecem relacionar-se ao modo como Coimbra (1995) refere-se aos movimentos pedagógicos que não se interrogam sobre a escola na condição de instituição social. Ela destaca que, assim como a Psiquiatria Institucional não questiona o solo ou o enquadre de sua atuação, a Psiquiatria, a Pedagogia Institucional não indaga a escola como tal. Nesses movimentos, as transformações são introduzidas nas relações internas aos espaços em questão. De modo análogo, o apoio desenvolve-se no contexto do Sistema Único de Saúde, o qual consiste em uma política de Estado, que se desenvolve na própria maquinaria estatal e não prescinde dela para operar.

Assim, o Estado não é posto em questão pelo apoio, processo que se dá sempre no interior da máquina estatal, com diferentes gradaçôes de abertura ao exterior, ao Fora do Estado. A cogestão, desse modo, parece ser uma transformação nos modos tradicionais de gerir, sem radicalizar, contudo, no que diz respeito à recusa da heterogestão. Talvez pela frequente experimentação da rigidez desses espaços de trabalho é que a produção de pequenas rupturas tem sido a aposta 
vislumbrada por algumas vertentes do apoio. Afinal, "o Estado não se define pela existência de chefes, e sim pela perpetuação ou conservação de órgãos de poder a preocupação do Estado é conservar" (Deleuze \& Guattari, 2002, p. 19).

Em alguns espaços, porém, a noção de cogestão vem acompanhada da ideia de que os fóruns em que ela é exercida são lugares de representação, os quais assumem a forma de colegiados gestores, conselhos ou grupos de trabalho. São desenhos que pressupõem que os grupos tenham homogeneidade, tenham identidade e que possam, por esse motivo, ter porta-vozes. E que o modo legítimo de se expressar é passar pela intermediação de um porta-voz para chegar nesse espaço coletivo. Dessa perspectiva, já que sempre há uma regulação externa, seja ela colegiada ou não, estaremos sempre no âmbito da heterogestão.

A esse respeito, Cecilio (2007, p. 350), ao afirmar que "a incontornável racionalidade instrumental que coloniza as organizaçôes, que cobra, de forma inapelável, práticas de controle e objetivação por parte de quem ocupa funções gerenciais ou de "chefia", lança o seguinte questionamento: é possível pensar a gestão na saúde numa perspectiva libertária e inovadora?

É possível inventar um novo modo de exercer a "função administrativa", no sentido dado por Henri Fayol há um século, que não seja a busca permanente de controle dos autogovernos dos trabalhadores, na medida em que esses nem sempre caminham na direção dos "objetivos organizacionais". Imperativo do controle, seja por meio de práticas explícitas, verticais, seja por intermédio de mecanismos menos evidentes, "participativos e democratizantes" (Cecílio, 2007, p. 350).

Nesse sentido, o autor aponta que o apoio Paidéia, o qual constituiria um eixo de cogestão, "objetivando a co-constituição de trabalhadores com capacidade para articular os próprios valores e interesses com a racionalidade dos outros, do coletivo e das organizaçôes", pode ser um poderoso instrumento de heteronomia quando "operado pelo governante" e nos tem colocado novos e mais complexos problemas, entre os quais o fato de o "apoio" vir "misturado" com as outras seis funções gerenciais, quando o "apoiador" ocupa um lugar na hierarquia formal de autoridade da organização. Segundo ele, "temos colocado uma excessiva expectativa sobre a potencialidade da cogestão de conseguir realizar a complexa e almejada (pelo governante) compatibilização dos interesses individuais, fragmentados, centrífugos, 'mesquinhos' e a tão desejada racionalidade organizacional" (Cecílio, 2007, p. 362-363).

Por essa razão, entende que a capacidade de aprender a interrogar o mundo do trabalho, antes de propor, aprioristicamente, conceitos e/ou modos muitos prescritivos de se fazer a gestão, deve ser o ponto de partida de toda pretensão 
de se conduzirem mudanças verdadeiras na forma de se fazer a gestão e de se organizar o cuidado em saúde.

Os dispositivos de gestão, se é que podemos chamá-los assim, são o próprio ato de interrogar. Talvez o mais difícil seja não pretender penetrar nesse mundo já armado com fórmulas, definições prévias de modelos, métodos ou arranjos de intençōes "democratizantes", e conseguir construir uma postura de interrogação do mundo do trabalho, no seu dia a dia concreto. Penso, cada vez mais, que interrogar é o "método" [...]. O uso, portanto, de conceitos em movimento (Cecílio, 2007 p. 348).

Nesse processo de sustentação de posicionamentos institucionais e de problematização da prática do apoio, é corrente a ideia de que o apoio é uma prática que se faz em posição de exterioridade. Necessariamente, o apoiador é tido como agente externo à equipe ou estabelecimento que irá apoiar, como "elemento externo ao grupo que, baseado na escuta e estabelecimento de vínculos com o mesmo, conduz um processo de análise e revisão coletiva e de reflexão do modo como os integrantes do serviço o articulam" (Furtado, 2001, p. 175).

Essa discussão do lugar no qual o apoiador opera remete-nos a alguns aspectos históricos do processo de institucionalização da própria Análise Institucional. Rodrigues (2004) refere a construção habitual de uma sinonímia entre a Análise Institucional e as intervençôes a pedido, as quais são concebidas como aquelas em que um especialista em grupos e instituições é chamado e vem de fora do campo problemático-profissional vivido pelos agentes, supostamente apto a revelar verdades escondidas e a restaurar funcionalidades perdidas.

Para a autora, estabeleceu-se aí um modelo de intervenção socioanalítica. E como novo produto no mercado, a Análise Institucional Socioanalítica se vê impelida a explicitar sua diferença frente aos "concorrentes". Embora se saiba que ela trabalha com conceitos que não se confundem com os de outros tipos de intervenção, pode-se encomendá-la como qualquer outra atividade mercantil. Sabe-se também que, com ela, a instituição não se confunde com o estabelecimento, e essa distinção é facilitada pela temporária interrupção das análises internas, mas, também por isso, cristaliza-se uma relação externa de clientela, conforme esclarece o seguinte trecho:

A distinção entre análise interna conduzida por alguém que pertence a um estabelecimento ou organização e externa efetuada por um interventor vindo "de fora" tem sentidos diversos conforme a encaremos via história das ideias ou via história institucional. No primeiro caso, trata-se de um equívoco teórico: ninguém está fora das instituições, por mais "externo" que seja a um estabelecimento ou organização. No segundo, remete às virtuais diferenças de poder de provocação que a análise institucional teve (e tem) em cada um dos casos (Rodrigues, 2004, p. 142). 
Novas questôes vão aparecendo em relação à prática do apoio, quando nos propusemos a pensar sobre o lugar institucional do apoiador. Se ele conformar uma nova profissão, corre-se o risco de restringir sua operacionalização, de engessar processos que supostamente seriam catalisadores de mudanças no SUS e de burocratizar algo que veio para conectar redes e transversalizar análises coletivas. É o que problematiza Merhy (2010, p. 435), quando escreve: "um apoiador que não se posicione a partir de um lugar de dispositivo é de fato recurso de um projeto moralmente já posicionado, o qual tem tantos projetos a priori que acaba traindo as suas próprias intenções discursivas de acolher a diferença”.

A esse respeito, Oliveira (2011) afirma o entendimento de que a constituição dos papéis de "apoiador" e de "apoiado" coemergem em ato no encontro, o que nos obriga a considerar a dificuldade de conciliação entre os arranjos fixos de organização do processo de trabalho em saúde e a variabilidade dos problemas e dos saberes e práticas que podem resolvê-los, os quais, muitas vezes, não respeitam a lógica dos arranjos fixos. Por arranjos fixos, entendem-se as

maneiras de pensar a organização dos processos de trabalho tomando as relações a partir de lugares institucionais fixos como se estes correspondessem sempre aos mesmos papéis e poderes constituídos e cristalizados, desconsiderando a dinâmica e as possibilidades de transversalização das relações saber-poder (p. 39).

\section{CONSIDERAÇÕES FINAIS}

A partir dos pontos ora discutidos, podemos entrever algumas razóes pelas quais o apoio tem sido frequentemente circunscrito como prática que se afasta das intervenções institucionalistas. Ainda assim, apostamos que a "democratização permanente e generalizada" segue como pauta fundamental na agenda do movimento sanitário e, portanto, ideia capaz de sustentar práticas de apoio. Em concordância com Lourau, entendemos que

[...] de fato, se o projeto autogestionário consiste não em tornar o indivíduo independente dos poderes, mas, ao contrário, em fazê-lo mestre dos poderes, ou seja, em socializar cada vez mais o Estado, a economia, a técnica e outras instâncias que até hoje funcionavam como destino exterior e inexorável, a autogestão aparece como a encarnação da ideologia democrática nas formas sociais reais, graças à ação instituinte dos indivíduos e não apenas à ação reguladora do direito. Instaurar a autogestão nada mais é do que desencadear um processo de democratização permanente e generalizada (Lourau, 2004b, p. 63).

Ao encontro do que aponta Coimbra, parece que, no limite, a intervenção institucionalista é uma empresa impossível: "contrariamente aos trabalhos dos 
psicossociólogos intervencionistas e conselheiros em organização, seu objeto não é uma terapia social, um melhoramento, mas, ao contrário, uma subversão do instituído. Quem pode pedi-la?" (Coimbra, 1995, p. 71).

De todo modo, a "função apoio" consiste em auxiliar na gestão e organização de processos de trabalho, na construção de espaços coletivos onde os grupos analisam, definem tarefas e elaboram projetos de intervenção. E isso só se faz ao colocarmos em análise, coletivamente, os processos de trabalho. A atuação dos apoiadores incide, portanto, no engajamento no trabalho de forma a ampliar a capacidade de análise, não como reconhecimento do que verdadeiramente se passa, mas como possibilidade de habitar o plano de coemergência das formas e de abri-las a outras composições possíveis e à intervenção dos coletivos e sujeitos forjados no processo. Trata-se, portanto, de uma tecnologia relacional. O método requer que o apoiador se coloque ao lado dos sujeitos na análise de seus processos de trabalho de modo a deixar-se afetar, nos coletivos, às formas autoritárias de atenção e gestão, e procure instrumentos que provoquem desvios, acolhendo e fortalecendo o que no grupo se desloca desses modelos.

Assim, ao intervir na possibilidade de autoanálise e autogestão dos coletivos no contexto das redes de saúde, a função apoio está em posição de reciprocidade em relação à intervenção socioanalítica. Isto é, à medida que a autogestão é um dispositivo de grupo que não se reduz a um modo de governar e, tampouco, pode estar ligada à noção de autorreferenciamento, pode-se afirmar que a aposta do apoio, em sua perspectiva estratégico-metodológica, é socioanalítica. É por essa via que afirmamos o apoio como ferramenta para autoanálise e autogestão de coletivos no SUS.

Desdobra-se daí uma preocupação: distinguir modos de apoio, tentando circunscrevê-los e categorizá-los, pode consistir em uma perigosa armadilha. Ao fazê-lo, podemos cair num discurso transcendental que vislumbra definir a priori qual apoio estamos desenvolvendo. Não seria na imanência das práticas que isso se vai fazendo? 


\section{REFERÊNCIAS}

Aguiar, K. F. \& Rocha, M. L. (2007). Micropolítica e o exercício da pesquisaintervenção: referenciais e dispositivos em análise. Psicologia: Ciência e Profissão, 27(4), 648-663.

Barros, M. E. B; Guedes, C. R. \& Roza, M. M. R. (2011). O apoio institucional como método de análise-intervenção no âmbito das políticas públicas de saúde: a experiência em um hospital geral. Ciência \& Saúde Coletiva, 16(12), 48034814.

Benevides, R. \& Passos, E. (2005). A humanização como dimensão pública das políticas de saúde. Ciência \& Saúde Coletiva, 10(3), 561-571.

Bertussi, D. C. (2010). O apoio matricial rizomático e a produção de coletivos na gestão municipal em saúde. Tese (Doutorado em Clínica Médica)- Universidade Federal do Rio de Janeiro, Faculdade de Medicina.

BRASIL. (2008). Ministério da Saúde. HumanizaSUS: política nacional de humanização. Documento base para gestores e trabalhadores do SUS. $4^{\mathrm{a}}$ ed. Brasília: Ministério da Saúde.

Campos, G. W. S. (1998). O anti-Taylor: sobre a invenção de um método para co-governar instituições de saúde produzindo liberdade e compromisso. Caderno Saúde Pública, 14(4), 863-870.

Campos, G. W. S. (2000). Um método para análise e co-gestão de coletivos: a constituição do sujeito, a produção de valor de uso e a democracia em instituiçōes: o método da roda. São Paulo: Hucitec.

Campos, G. W. S. (2003). Saúde paidéia. São Paulo: Hucitec.

Campos, G. W. S. (2007a). Clínica e saúde coletiva compartilhadas: teoria Paidéia e reformulação ampliada do trabalho em saúde. In G.W.S. Campos, M.C.S., Minayo, M., Akerman, M. Drumond Júnior, \& Y.M. Carvalho (Orgs.). Tratado de saúde coletiva (pp. 41-80). São Paulo-Rio de Janeiro: Hucitec-Fiocruz.

Campos, G. W. S. (2007b). Comentários sobre analogias e diferenças entre os métodos Paidéia e o "interrogativo". Interface Comunicação, Saúde, Educação, 11(22), 352-354.

Campos, G.W.S. (2008). SUS depois de vinte anos: reflexões sobre o direito à 
atenção à saúde. BIS - Boletim do Instituto de Saúde. Edição Especial de 20 anos do SUS. pp. 36-38.

Ceccim, R. B. (2005). Educação permanente em saúde: desafio ambicioso e necessário. Interface Comum Saúde Educação 9(16), 161-177. Recuperado a partir de http://www.scielo.br/pdf/icse/v9n16/v9n16a13.pdf

Ceccim, R. B. (2007). "Um sentido muito próximo ao que propõe a educação permanente em saúde”!: O devir da educação e a escuta pedagógica da saúde. Interface-Comunicação, Saúde, Educação, 11(22), 358-361.

Cecílio, L. C. de O. (2007). O "trabalhador moral” na saúde: reflexões sobre um conceito. Interface-Comunic, Saúde, Educ, 11(22), 345-63.

Coimbra, C. M. B. (1995). Os caminhos de Lapassade e da análise institucional: uma empresa possível. Revista do Departamento de Psicologia da UFF, 7(1), 52-80.

Deleuze, G. \& Guattari, F. (2002). Mil platôs: capitalismo e esquizofrenia. In P. P. Peter, C. Janice (Trads.). (Vol. 5). São Paulo: Editora 34.

Guba, E.G. \& Lincoln, Y. S. (2011). Avaliação de quarta geração. In H. Beth (Trad.) Campinas: UNICAMP.

Fleury, S. (2009). Reforma sanitária brasileira: dilemas entre o instituinte e o instituído. Ciencias Saude Coletiva, 14(3), 743-752.

Furtado, J.P. (2001). Um método construtivista para a avaliação em saúde. Ciência \& Saúde Coletiva, 6(1), 165-181.

Lourau, R. (1993). Análise institucional e práticas de pesquisa. Rio de Janeiro: UERJ.

Lourau, R. (2004a). Pequeno manual de Análise Institucional. In S. Schneider (Trad.), S. Altoé, (Ed.). René Lourau: analista institucional em tempo integral. (pp. 122-127). São Paulo: Hucitec.

R. Lourau (2004b). O instituinte contra o instituído. In S. Schneider (Trad.), S. Altoé, (Ed.). René Lourau: analista institucional em tempo integral. (pp. 47-65). São Paulo: Hucitec.

Merhy, E. E. (2002). Saúde: a cartografia do trabalho vivo. São Paulo: Hucitec.

Merhy, E.E. (2010). Micropolítica do encontro intercessor apoiador-equipe, 
substrato para um agir intensivista. Saúde em Debate, 34(86), 433-435.

Núcleo Técnico da Política Nacional de Humanização; Ministério da Saúde; Secretaria Executiva (2008). HumanizaSUS: política nacional de humanização. (4a. ed.). Documento base para gestores e trabalhadores do SUS.

Oliveira, G. N. (2011). Devir apoiador: uma cartografia da função apoio. Tese (Doutorado em Ciências Médicas). Universidade Estadual de Campinas, Campinas.

Paulon, S. M., Pasche, D. F., \& Righi, L. B. (2014). Função apoio: da mudança institucional à institucionalização da mudança. Interface: comunicação, saúde, educação. Botucatu. 18(1), 809-820.

Pasche, D.F. \& Passos, E. (2010a). Inclusão como método de apoio para a produção de mudanças na saúde: aposta da política de humanização da saúde. Saúde e Debate, 34, 423-32.

Pasche, D.F. \& Passos, E. (2010b). O lugar do método na Política Nacional de Humanização: aposta para uma experimentação democrática radical. Saúde e Debate, 34, 439-447.

Pasche, D. F., Passos, E., \& Hennington, E. A. (2011). Cinco anos da Política Nacional de Humanização: trajetória de uma política pública Five years of the National Policy of Humanization: the trajectory of a public policy. Ciência Saude Coletiva, 16(11), 4541-4548.

Passetti, E. (2002). Heterotopias anarquistas. Verve, (2).

Penido, C. M. F. (2013). Apoio matricial em saúde mental no contexto da saúde coletiva. in S. M., Paulon, \& R. Neves, (Org.). Saúde mental na atenção básica: a territorialização do cuidado. (pp.17-38.). Porto Alegre: Sulina,

Rodrigues, H. B. C. (2004). Análise Institucional francesa e transformação social: o tempo (e contratempo) das intervençôes. In H. B. C., Rodrigues, \& S. Altoé, (Orgs.) Saúde loucura n. 8: análise institucional. (pp.115-164). São Paulo: Hucitec.

Santos-Filho, S. B. \& Barros, M. E. B. (2007). A base político-metodológica em que se assenta um novo dispositivo de análise e intervenção no trabalho em saúde. In: S.B. Santos-Filho, \& M.E.B., Barros, (Org.). Trabalhador da saúde: muito prazer! Protagonismo dos trabalhadores na gestão do trabalho em saúde. (pp. 123-142). Ijuí: Unijuí. 
Vasconcelos, M. F. F \& Morschel, A. (2009). O apoio institucional e a produção de redes: do desassossego dos mapas vigentes na Saúde Coletiva. InterfaceComunicação, Saúde, Educação, 13(1), 729-738.

Yasui, S. (2010). Rupturas e encontros: desafios da reforma psiquiátrica brasileira. Rio de Janeiro: Fiocruz. 